\author{
SERIES "NONINVASIVE MONITORING OF AIRWAY INFLAMMATION" \\ Edited by H. Magnussen and F.E. Hargreave \\ Number 2 in this series
}

\title{
Update on sputum methodology
}

\author{
O. Holz*, J. Kips*, H. Magnussen*
}

Update on sputum methodology. O. Holz, J. Kips, H. Magnussen. (C) ERS Journals Ltd 2000. ABSTRACT: Over the past few years cellular and biochemical sputum examinations have become important instruments to assess airway inflammation. The aim of this review is to summarize new methodological developments and aspects, which are currently under investigation.

The use of isotonic saline has increased safety of inductions in patients with severe asthma and in children. The origin of sputum is better understood, as is the need to standardize the volume and duration of induction. It also needs to be borne in mind that the induction procedure itself is able to cause changes in sputum composition. However, the basic induction and processing procedures have not changed much over the last few years, and therefore the method is still time consuming. The analysis of ECP in lysed sputum cells as a marker for the number of esinophils has been suggested to overcome this problem, but needs further validation. Furthermore, storage of sputum has been studied, as well as early fixation or freezing of sputum cells to elongate the time between induction and processing. Differential cell counts by flow cytometry are still difficult, but the method has increased knowledge concerning lymphocyte subsets and the activation status of sputum cells.

The use of induced sputum to noninvasively measure airway inflammation in clinical trials will offer additional information, but the proper use and interpretation of sputum outcome parameters will need further investigation.

Eur Respir J 2000; 16: 355-359.

\author{
*Krankenhaus Grosshansdorf, Zentrum \\ für Pneumologie und Thoraxchirurgie, \\ Grosshansdorf, Germany, "Dept of Res- \\ piratory Diseases, University Hospital, \\ Ghent, Belgium.
}

Correspondence: O. Holz Krankenhaus Grosshansdorf Zentrum für Pneumologie und Thoraxchirurgie D-22927 Grosshansdorf Germany Fax: 494102692295

Keywords: Airway inflammation cell counts

eosinophil cationic protein

induced sputum

isotonic saline

methodology

Received: September 11999

Accepted after revision April 122000
Interest in sputum examination as a marker of airway inflammation in airway diseases has increased a lot since the first report of PIN et al. in 1992 [1]. A series of reviews and editorials have been published covering the development and application of the methods [2-11]. It has been shown that, provided standard precautions are taken into account, sputum induction can be used safely $[12,13]$. The two techniques of examination used today, with their advantages and drawbacks, have been described in detail and issues like reproducibility, validity and reliability have been discussed $[14,15]$. A very detailed report on one method of sputum induction was published in 1997 [16]. The aim of this review is to discuss the recent considerations regarding sputum induction and examination, which have implications for safety, study design and use in clinical trials or practice.

\section{Increasing the safety of sputum induction}

In most of the recently published studies hypertonic saline $(3-5 \%)$ has been used for sputum induction, because isotonic saline was shown to result in a lower success rate
[17]. However, it has now been demonstrated in two studies in severe asthma that induction with isotonic saline is better tolerated in these patients and is often sufficient to induce sputum $[18,19]$. For patients with severe airway diseases it therefore seems advisable to start the induction with isotonic saline and to continue with hypertonic saline only if this is not successful. Together with the other recommended safety precautions, namely premedication with $\beta_{2}$-agonists and lung function monitoring throughout the induction procedure, this could further reduce the risk of bronchoconstriction. Another aspect concerning safety of sputum inductions was reported by Pizzichini et al. [19, 20]. They observed that the overuse of $\beta_{2}$-agonists the day before sputum induction reduced the protective effect of premedication. Therefore, a patient should always be asked about the frequency of bronchodilator use before a sputum induction.

Studies in children indicate that sputum can be induced safely from the age of 7 yrs onwards. The success rate using hypertonic saline was similar to the results obtained in adults. Similarly, the use of isotonic saline during asthma exacerbations was shown to result in the production of a sufficient sample, without adverse effects [21, 22].

Previous articles in this series: No. 1: L. Jayaram, K. Parameswaran, M.R. Sears, F.E. Hargreave. Induced sputum cell counts: their usefulness in clinical practice. Eur Respir $J$ 2000; 16: 150-158. 


\section{Inflammatory response to inhalation of hypertonic saline}

The relative noninvasiveness of sputum induction renders this technique particularly useful for repeated assessment of airway inflammation in the longitudinal follow-up of patients. However, when designing follow-up studies, it has to be taken into account that repeated inductions within short intervals can alter the composition of sputum. Sputum induction is followed within $6 \mathrm{~h}$ by an increase in sputum neutrophil numbers, which lasts for at least $24 \mathrm{~h}[23$, 24]. This effect is not only observed after induction with intermediate and high output nebulizers, but also with relatively low output nebulizers [25]. The exact cause of this inflammatory response is unknown. It has been speculated that additional fluid within the airways, hypertonicity of inhaled solutions, frequent coughing during induction or bacterial contamination leading to the inhalation of endotoxin $[26,27]$ are contributing factors. It has therefore been re-emphasized that laboratory procedures including preparation, handling or storage of solutions should be designed in such a way that bacterial contamination of solutions or nebulizers are avoided. Whether isotonic saline can have a similar effect has not been tested so far.

\section{The origin of sputum}

The cellular and biochemical composition of sputum has been compared to bronchial wash (BW) and bronchoalveolar lavage (BAL). Some of these studies include an additional comparison with either bronchial biopsies or peripheral blood [28-32]. The cellular composition of sputum correlates rather well with BW or BAL, but to a lesser extent with bronchial biopsies. These observations can at least partly be attributed to differences in the lumenal and mucosal phase of airway inflammation. In addition, it can be argued that these various techniques collect cells from different locations within the airway tree. Studies performing segmental lavages at different depths within the airways illustrate that the proportion of neutrophils decreases from central $(20-30 \%)$ to peripheral airways $(<2 \%)$, with a corresponding increase in the proportion of macrophages [33]. Based on these observations and comparative data with BW and BAL, it seems likely that sputum is derived from the central more proximal airways, whereas BW and BAL sample more the peripheral airways and the alveolar compartment. Consecutive sputum samples produced during one sputum induction also display a neutrophil gradient [34-36], and it was assumed that this reflects sampling of secretions from different depths of the airways. This was further supported by a report of GERSHMAN et al. [37], who found decreasing concentrations of mucin and increasing concentrations of surfactant in consecutive sputum samples. In subjects with high proportions of sputum eosinophils, a decrease in the percentage of these cells during induction has also been noted $[34,37]$. In two studies sputum macrophages were compared with alveolar macrophages obtained by BAL. Although immunocytochemical staining with a series of markers revealed a more mature phenotype of sputum macrophages [38], it could be shown by flow cytometry that the sputum macrophages were active cells and capable of host defence functions [39].

It has to be noted that the progressive change in the composition of sputum is also influenced by the underlying

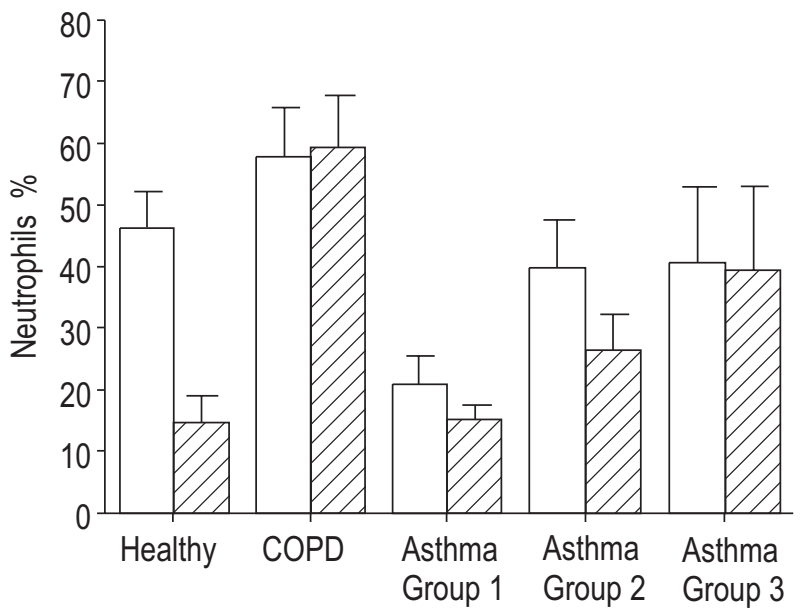

Fig. 1. - Changes in sputum composition during sputum induction in different groups of patients. Mean \pm SEM of 11 healthy subjects, 10 patients with chronic obstructive pulmonary disease (COPD), 11 patients with mild asthma (Group 1: $\beta_{2}$-agonists only), 12 patients with mild to moderate asthma (Group 2: $\beta_{2}$-agonists and inhaled steroids) and seven patients with moderate to severe asthma (Groups 3: inhaled and oral steroids) are given. $\square$ : sputum produced in inhalation period $1 ; \mathbb{Z}$ : sputum produced in inhalation period 2. Data are from Ref. [35].

disease process (fig. 1). In severe asthma or in chronic obstructive pulmonary disease the decline in sputum neutrophil numbers is far less pronounced than in normal subjects or in mild asthma [35]. Overall however, because changes in the composition of sputum can occur throughout the induction period, it seems advisable to standardize the duration of induction, in order to reduce inter- and intra-subject variability upon repeated analysis.

\section{Approaches to make sputum examinations less time- consuming}

The method of sputum induction has many advantages, but it has a few major drawbacks that limit its use in daily clinical practice. These include the need for dedicated, highly qualified laboratory technicians and the time consuming nature of the technique. It can be estimated that even if a patient produces a suitable sputum sample within 10 min of starting induction, the total time required for inducing, processing and performing a differential cell count will amount to $\sim 100 \mathrm{~min}$. The method has therefore been used mainly for research and less in clinical practice. In addition, the need to process sputum within $2 \mathrm{~h}$ after induction limits the amount of patients that can be examined in parallel and restricts a use of the method in most outpatient clinics.

Two methods were recently suggested to overcome the problems, that storage of sputum could cause a lower quality of cytospins and a change in sputum composition [40]. One method consists of simultaneous homogenization and fixation of freshly expectorated sputum with Saccomanno's fixative plus $0.2 \%$ dithiothreitol (DTT) [41] in order to enable longer storage. This method is currently used for automated sputum cytometry, albeit that differential cell counts are still difficult to perform due to cellular shrinkage after fixation. The second and more promising approach was reported by Popov et al. [42] who demonstrated that the freezing of cells using dimethylsulphoxide to avoid water crystalization does not 
impair cellular morphology to an extent that affects the differential cell count. Preliminary data show a good correlation between frozen samples and corresponding freshly processed aliquots [43].

A different approach to simplify sputum analysis was chosen by GiBSON et al. [44]. Instead of preparing cytospins to quantify eosinophils, the most extensively validated cellular component in sputum, they lysed the cell pellet after homogenization and measured the amount of eosinophilic cationic protein (ECP) released as a marker of the number of eosinophils present in sputum. Although the amount of time necessary for the analysis of ECP is $\sim 3 \mathrm{~h}$, its advantage is that it can be automated, therefore making it cheaper. The good correlation between the number of eosinophils and the concentration of ECP in the cell lysate suggests that this could be an easier way to perform large scale studies. This concept, however, requires further validation.

Flow cytometry could be another alternative for automating sputum differential cell counts [45]. However, on sputum, this technique is fraught with methodological difficulties. While eosinophils can easily be detected on cytospins, using flow cytometry it remains difficult to separate them from neutrophils [46]. Currently the most promising method, is to use the depolarized orthogonal light scattering technique [47]. This method was also used in a recent report [48] analysing surface markers on eosnophils in whole exspectorate. The reliability of flow cytometry to measure the percentage of eosinophils in sputum needs to be further determined. Although cell sorting by flow cytometry is able to enrich eosinophils by $3-95 \%$ [48], discriminating eosinophil proportions under $5 \%$ is very difficult. Therefore the sensitivity of this outcome measure needs to be increased if eosinophil percentages are to be monitored in the range of a proposed $2 \%$ cut-off level, discerning normal from asthmatic individuals [49].

\section{Identifying cellular subtypes and cellular activation}

In addition to the cellular sputum composition there is increasing interest in the analysis of cellular subtypes or cellular activation. The use of flow cytometry allows simultaneous staining of cells with different markers. Therefore this method is applicable for this kind of investigation. Flow cytometry revealed elevated levels of CD11b, a marker for eosinophil activation, in asthmatic subjects as well as increased levels of intercellular adhesion molecule (ICAM)-1, L-selectin and human leukocyte antigen (HLA)-DR as compared to blood, very likely due to the process of migration into the lungs $[45,48]$. Furthermore, it was shown that subjects with asthma have a different sputum lymphocyte profile compared to nonasthmatic smoking control subjects [50]. Flow cytometric analysis of lymphocytes showed an increase in CD4+ T-cells and T-cells expressing ICAM-1 and decreased proportions of CD16+ cells in the sputum of asthmatic patients [51]. Comparison of sputum and BAL demonstrated that neutrophils and CD4+ T-cells were strongly correlated in these different compartments. In both sputum and BAL a higher proportions of CD4+ T-cells and lower proportion of CD8+ cells and CD19+ T-lymphocytes were found compared to blood. Sputum also had a higher
CD4+/CD8+ ratio [29]. As sputum has to be homogenized before flow cytometry, a possible effect of the DTT treatment on surface markers has to be considered. After treatment of blood leukocytes with DTT, both increased and decreased levels of surface markers could be detected, indicating that DTT is able to destroy epitopes, but can also result in a better access of antibodies to their respective antigen [52]. In most studies published so far on sputum lymphocyte subsets, checksum controls were not included. Although more difficult in sputum as compared to blood or BAL [53], the plausibility of results, can be controlled by calculating whether $\mathrm{CD} 4++\mathrm{CD} 8+=$ $\mathrm{CD} 3+$ and if $\mathrm{CD} 3++\mathrm{CD} 19++\mathrm{CD} 3-\mathrm{CD} 16+/ \mathrm{CD} 56+=$ $100 \%$.

\section{Induced sputum in clinical trials}

As asthma is considered to be a chronic inflammatory disorder of the airways, it seems logical to include a marker of airway inflammation as one of the outcome measures in clinical trials. Induced sputum would appear particularly useful in this respect. Recent studies indicate that induced sputum offers a more accurate assessment of airway inflammation than other noninvasive markers such as blood eosinophil count, serum ECP or exhaled nitric oxide [49, 54]. As already indicated, sputum induction is less invasive than other direct markers of airway inflammation such as bronchial biopsies or BAL, and has been shown to be safe even in severe asthma $[13,19]$. In addition, the technique has been extensively validated over the past few years, both with regard to its responsiveness to intervention and conformity to other parameters of airway inflammation [3]. Of particular interest is the observation that, as for biopsies [55], the composition of sputum can correlate poorly with other indices of disease activity such as symptom score, baseline forced expiratory volume in one second (FEV1) or the provocative concentration causing a $20 \%$ fall in FEV1 methacholine [56-59]. This implies that combining sputum analysis with other outcome measures offers additional information, instead of merely duplicating existing data.

Obviously, when using induced sputum as an outcome measure in clinical trials, proper attention should be paid to the various methodological issues outlined in the previous sections. In addition, a number of issues remain to be further clarified. Firstly, it has to be remembered that sputum has been validated predominantly with respect to eosinophils, expressed as percentage of the total cell fraction. Components of sputum that represent other aspects of the inflammatory process in asthma, such as airway remodelling, remain to be further identified and validated. Potential candidates include elastase or matrix metalloproteinases (MMP) such as MMP-9. These enzymes could be involved in the remodelling process and have recently been shown to be present in increased concentrations in sputum supernatant of asthmatics $[60,61]$.

Secondly, even when only considering eosinophil numbers in sputum, other questions remain. Most of the crosssectional studies conducted so far, illustrate the wide range in eosinophil numbers in sputum samples obtained from patients, who otherwise have similar clinical and lung function characteristics $[14,31,62]$. This needs to be taken into account when designing clinical trials, as this can 
cause unforeseeable differences in baseline sputum eosinophil numbers between groups that otherwise appear totally matched [63]. Stratifying for sputum eosinophil numbers might therefore prove necessary. More importantly, the clinical relevance of these differences in sputum eosinophilia are unknown. As a consequence, it is neither clear whether one of the goals of asthma treatment should be to keep sputum eosinophils beneath a certain threshold, nor is it known what constitutes a clinically meaningful response in sputum eosinophil numbers. This together with the interindividual variability in sputum eosinophil numbers, has obvious repercussions on the power calculation of studies that aim to conclusively compare different treatment strategies in asthma.

\section{Conclusion}

Over the past few years the method of sputum induction has developed into a powerful noninvasive tool in the investigation of airway diseases. However, many questions remain to be answered. These include methodological aspects in the analysis of sputum cells and fluid phase markers, as well as finding ways to make sputum examinations less time consuming. For clinical trials it will be important to further elucidate the clinical meaning of changes in sputum composition and the potential benefit for patients of including sputum examinations to monitor or optimize treatment.

\section{References}

1. Pin I, Gibson PG, Kolendowicz R, et al. Use of induced sputum cell counts to investigate airway inflammation in asthma. Thorax 1992; 47: 25-29.

2. Hansel TT, Walker C. The migration of eosinophils into the sputum of asthmatics: the role of adhesion molecules. Clin Exp Allergy 1992; 22: 345-356.

3. Kips JC, Fahy JV, Hargreave FE, Ind PW, in't Veen JCCM. Methods for sputum induction and analysis of induced sputum: a method for assessing airway inflammation in asthma. Eur Respir J 1998; 11: Suppl. 26, 9s-12s.

4. Kips JC, Pauwels RA. Noninvasive indicators of airway inflammation: induced sputum in allergic diseases. Eur Respir Rev 1998; 8: 1095-1097.

5. Kips JC, Peleman RA, Pauwels RA. Methods of examining induced sputum: do differences matter? Eur Respir J 1998; 11: 529-533.

6. Pavord ID, Pizichini MM, Pizzichini E, Hargreave FE The use of induced sputum to investigate airway inflammation. Thorax 1997; 52: 498-501.

7. Hargreave FE, Pizichini E, Pizichini M. Induced sputum examination. J Allergy Clin Immunol 1998; 101: 569-570.

8. O'Byrne PM, Inman MD. Induced sputum to assess airway inflammation in asthma. Eur Respir J 1996; 9: 24352436.

9. Gibson PG. How to measure airway inflammation: induced sputum. Can Respir J 1998; 5; Suppl A, 22A-26A.

10. Magnussen $\mathrm{H}$, Holz O. Monitoring airway inflammation in asthma by induced sputum. Eur Respir J 1999; 13: 5-7.

11. Fahy JV. A safe, simple, standardized method should be used for sputum induction for research purposes. Clin Exp Allergy 1999; 28: 1047-1049.

12. Wong HH, Fahy JV. Safety of one method of sputum induction in asthmatic subjects. Am J Respir Crit Care Med 1997; 156: 299-303.
13. de la Fuente PT, Romagnoli M, Godard P, Bousquet J, Chanez P. Safety of inducing sputum in patients with asthma of varying severity. Am J Respir Crit Care Med 1998; 157: 1127-1130.

14. Pizzichini E, Pizzichini MM, Efthimiadis A, et al. Indices of airway inflammation in induced sputum: reproducibility and validity of cell and fluid-phase measurements. Am J Respir Crit Care Med 1996; 154: 308-317.

15. in't Veen JCCM, de Gouw HW, Smits HH, et al. Repeatability of cellular and soluble markers of inflammation in induced sputum from patients with asthma. Eur Respir J 1996; 9: 2441-2447.

16. Efthimiadis A, Pizzichini E, Pizzichini MMM, Hargreave FE. Sputum examination for indices of airway inflammation: laboratory procedures. Canadian Thoracic Society 1997.

17. Popov TA, Pizzichini MM, Pizzichini E, et al. Some technical factors influencing the induction of sputum for cell analysis. Eur Respir $J$ 1995; 8: 559-565.

18. Pizzichini MMM, Pizzichini E, Clelland L, et al. Prednisone dependent asthma: inflammatory indices in induced sputum. Eur Respir J 1999; 13: 15-21.

19. Pizzichini MM, Pizzichini E, Clelland L, et al. Sputum in severe exacerbations of asthma: kinetics of inflammatory indices after prednisone treatment. Am J Respir Crit Care Med 1997; 155: 1501-1508.

20. Pizzichini E, Pizzichini MMM, Burigo AC. Sputum induction in stable steroid naive asthma: influence of prior use of $\beta_{2}$-agonist. Eur Respir J 1998; 12: 365s.

21. Gibson PG. Use of induced sputum to examine airway inflammation in childhood asthma. J Allergy Clin Immunol 1998; 102: S100-S101.

22. Twaddell SH, Gibson PG, Carty K, Woolley KL, Henry RL. Assessment of airway inflammation in children with acute asthma using induced sputum. Eur Respir J 1996; 9: 2104-2108.

23. Holz O, Richter K, Jörres RA, Speckin P, Mücke M, Magnussen $\mathrm{H}$. Changes in sputum composition between two inductions performed on consecutive days. Thorax 1998; 53: 83-86.

24. Nightingale JA, Rogers DF, Barnes PJ. Effect of repeated sputum induction on cell counts in normal volunteers. Thorax 1998; 53: 87-90.

25. Berlyne GS, Lemiere C, Hussack P, Efthimiadis A, Hargreave FE. Evaluation of repeated sputum inductions in asthmatic subjects. Eur Respir $J$ 1998; 12: 245s.

26. Sandstrom T, Bjermer L, Rylander R. Lipopolysaccharide (LPS) inhalation in healthy subjects increases neutrophils, lymphocytes and fibronectin levels in bronchoalveolar lavage fluid. Eur Respir J 1992; 5: 992-996.

27. Nightingale JA, Rogers DF, Hart LA, et al. Effect of inhaled endotoxin on induced sputum in normal, atopic, and atopic asthmatic subjects. Thorax 1998; 53: 563571.

28. Fahy JV, Wong H, Liu J, Boushey HA. Comparison of samples collected by sputum induction and bronchoscopy from asthmatic and healthy subjects. Am J Respir Crit Care Med 1995; 152: 53-58.

29. Pizzichini E, Pizzichini MM, Kidney JC, et al. Induced sputum, bronchoalveolar lavage and blood from mild asthmatics - inflammatory cells, lymphocyte subsets and soluble markers compared. Eur Respir J 1998; 11: 828834.

30. Maestrelli P, Saetta M, Di Stefano A, et al. Comparison of leukocyte counts in sputum, bronchial biopsies, and bronchoalveolar lavage. Am J Respir Crit Care Med 1995; 152: 1926-1931. 
31. Grootendorst DC, Sont JK, Willems LN, et al. Comparison of inflammatory cell counts in asthma: induced sputum vs bronchoalveolar lavage and bronchial biopsies. Clin Exp Allergy 1997; 27: 769-779.

32. Keatings VM, Evans DJ, O'Connor BJ, Barnes PJ. Cellular profiles in asthmatic airways: a comparison of induced sputum, bronchial washings, and bronchoalveolar lavage fluid. Thorax 1997; 52: 372-374.

33. Rankin JA, Marcy T, Rochester CL, et al. Human airway macrophages. A technique for their retrieval and a descriptive comparison with alveolar macrophages. $\mathrm{Am} \mathrm{Rev}$ Respir Dis 1992; 145: 928-933.

34. Holz O, Jörres RA, Koschyk S, Speckin P, Welker L, Magnussen $\mathrm{H}$. Changes in sputum composition during sputum induction in healthy and asthmatic subjects. Clin Exp Allergy 1998; 28: 284-292.

35. Richter K, Holz O, Jörres RA, Mücke M, Magnussen H. Sequentially induced sputum in patients with asthma or chronic obstructive pulmonary disease. Eur Respir $J$ 1999; 14: 697-701.

36. Belda J, Hussack P, Efthimiadis A, Dolovich M, Hargreave FE. Comparison of effect of time of inhalation and nebulizer output on cell counts. Am J Respir Crit Care Med 1999; 159: A848.

37. Gershman NH, Liu H, Wong HH, Liu JT, Fahy IV. Fractional analysis of sequential induced sputum samples during sputum induction: evidence that different lung compartments are sampled at different time points. $J$ Allergy Clin Immunol 1999; 104: 322-328.

38. Lensmar C, Elmberger G, Sandgren P, Sköld CM, Eklund A. Leukocyte counts and macrophage phenotypes in induced sputum and bronchoalveolar lavage fluid from normal subjects. Eur Respir J 1999; 12: 595-600.

39. Alexis NE, Becker S. Can airway cell phenotype and function predict disease severity? Use of sputum macrophages and neutrophils to evaluate surface marker expression and phagocytosis as predictors of asthma severity. Am J Respir Crit Care Med 1999; 159: A100.

40. Bettschart RW, El-Kushman H, Spanevello A, Myers JD, Shakur H, Ind PW. Effect of storage on differential cell counts in induced sputum from COPD patients, smokers and normal subjects. Am J Respir Crit Care Med 1998; 157: A812.

41. Nielsen L, Marek W, Köhler Ch, Khanavkar B, Muti A, Nakhosteen JA. Improvement of sputum preparation for automated cytometry. Am J Respir Crit Care Med 1998; 157: A365.

42. Popov T, Baleva M, Shenkada M, Boyanovski B. Changes in the cellular and fluid phase components of sputum in the specific antarctic environment. Eur Respir J 1998; 12: 438s.

43. Holz O, Saba B, Mücke M, Loppow D, Jörres RA, Magnussen H. Comparison of differential cell counts between frozen and native sputum samples. Eur Respir $J$ 1999; 14: 23s

44. Gibson PG, Woolley KL, Carty K, Murree-Allen K, Saltos N. Induced sputum eosinophil cationic protein (ECP) measurement in asthma and chronic obstructive airway disease (COAD). Clin Exp Allergy 1998; 28: 1081-1088.

45. Hansel TT, Braunstein JB, Walker C, et al. Sputum eosinophils from asthmatics express ICAM-1 and HLA-DR. Clin Exp Immunol 1991; 86: 271-277.

46. Loppow D, Böttcher M, Jörres RA, Gercken G, Magnussen $\mathrm{H}$. Flow cytometric detection of induced sputum eosinophils. Eur Respir J 1998; 12: 65s.

47. de Grooth BG, Terstappen LW, Puppels GJ, Greve J. Light-scattering polarization measurements as a new parameter in flow cytometry. Cytometry 1987; 8: 539544.

48. in't Veen JC, Grootendorst DC, Bel EH, et al. CD11b and l-selectin expression on eosinophils and neutrophils in blood and induced sputum of patients with asthma compared with normal subjects. Clin Exp Allergy 1998; 28: 606-615.

49. Pizzichini E, Pizzichini MM, Efthimiadis A, Dolovich J, Hargreave FE. Measuring airway inflammation in asthma: eosinophils and eosinophilic cationic protein in induced sputum compared with peripheral blood. $J$ Allergy Clin Immunol 1997; 99: 539-544.

50. Kidney JC, Wong AG, Efthimiadis A, et al. Elevated B cells in sputum of asthmatics. Close correlation with eosnophils. Am J Respir Crit Care Med 1996; 153: 540-544.

51. Louis R, Shute J, Biagi S, et al. Cell infiltration, ICAM-1 expression, and eosinophil chemotactic activity in asthmatic sputum. Am J Respir Crit Care Med 1997; 155: 466-472.

52. Loppow D, Böttcher M, Gercken G, Magnussen H, Jörres RA. Flow cytometric analysis of the effect of dithiothreitol on leukocyte surface markers. Eur Respir J 2000; 16: 316-323.

53. Loppow D, Böttcher M, Jörres RA, Gercken G, Magnussen H. Flow cytometric analysis of induced sputum lymphocyte subpopulations. Am J Respir Crit Care Med 1999; 159: A514.

54. Jatakanon A, Kharitonov S, Lim S, Barnes PJ. Effect of differing doses of inhaled budesonide on markers of airway inflammation in patients with mild asthma. Thorax 1999; 54: 108-114.

55. Crimi E, Spanevello A, Neri M, Ind PW, Rossi GA, Brusasco V. Dissociation between airway inflammation and airway hyperresponsiveness in allergic asthma. Am J Respir Crit Care Med 1998; 157: 4-9.

56. Rosi E, Ronchi MC, Grazzini M, Duranti R, Scano G. Sputum analysis, bronchial hyperresponsiveness, and airway function in asthma: results of a factor analysis. $J$ Allergy Clin Immunol 1999; 103: 232-237.

57. Jatakanon A, Lim S, Kharitonov SA, Chung KF, Barnes PJ. Correlation between exhaled nitric oxide, sputum eosinophils, and methacholine responsiveness in patients with mild asthma. Thorax 1998; 53: 91-95.

58. Polosa R, Renaud L, Cacciola R, Prosperini G, Crimi N, Djukanovic R. Sputum eosinophilia is more closely associated with airway responsiveness to bradykinin than methacholine in asthma. Eur Respir J 1998; 12: 551-556.

59. Yoshikawa T, Shoji S, Fujii T, et al. Severity of exerciseinduced bronchoconstriction is related to airway eosinophilic inflammation in patients with asthma. Eur Respir $J$ 1998; 12: 879-884.

60. Vignola AM, Riccobono L, Mirabella A, et al. Sputum metalloproteinase-9/tissue inhibitor of metalloproteinase1 ratio correlates with airflow obstruction in asthma and chronic bronchitis. Am J Respir Crit Care Med 1998; 158: 1945-1950.

61. Vignola AM, Bonanno A, Mirabella A, et al. Increased levels of elastase and alphal-antitrypsin in sputum of asthmatic patients. Am J Respir Crit Care Med 1998; 157: 505-511.

62. Fahy JV, Boushey HA. Effect of low-dose beclomethasone dipropionate on asthma control and airway inflammation. Eur Respir J 1998; 11: 1240-1247.

63. Pizzichini E, Leff JA, Reiss TF, et al. Montelukast reduces airway eosinophilic inflammation in asthma: a randomized controlled trial. Eur Respir J 1999; 14: 12-18. 